\title{
КЛИНИЧЕСКИЕ ХАРАКТЕРИСТИКИ ПАЦИЕНТОВ С ВПЕРВЫЕ ВЫЯВЛЕННЫМ САХАРНЫМ ДИАБЕТОМ 1 ТИПА И COVID-19. ОПЫТ ГОРОДСКОГО СТАЦИОНАРА
}

Ю.В. Тихонович',2, И.Г. Рыбкина', Т.Т. Князева', И.В. Гаряева', Ч.В. Дагбы', Е.В. Шредер', А.Б. Шимарова', А.Ю. Рыбанова', А.Н. Лазарева', Е.Е. Петряйкина ${ }^{1,3}$

'ГБУЗ «Морозовская детская городская клиническая больница Департамента здравоохранения города Москвы», г. Москва,

${ }^{2}$ ФГАОУ ВО «Первый Московский государственный медицинский университет им. И.М. Сеченова (Сеченовский университет)», г. Москва

${ }^{3}$ ФГАОУ ВО «Российский национальный исследовательский медицинский университет имени Н.И. Пирогова», г. Москва

ВВЕДЕНИЕ. В последнее время все чаще появляются публикации, свидетельствующие о том, что COVID19 является фактором риска развития тяжелого ДКА и гиперосмолярного гипергликемического синдрома у взрослых пациентов с декомпенсированным или впервые выявленным СД (СДВВ).

Данные об особенностях течения СД у пациентов детского возраста с COVID-19 ограничены отдельными сообщениями, в которых активно обсуждается роль SARS-CoV-2 как потенциального триггера ДКА.

Мы представляем клинические характеристики пациентов с СД и COVID-19, госпитализированных в Морозовскую детскую городскую клиническую больницу (МДГКБ) с марта 2020 г. по март 2021 года.

РЕзУЛЬТАТЫ. В исследование было включено 23 ребенка (12 девочек и 11 мальчиков) с СД (17 пациентов с СДВВ и 6 пациентов со стажным течением СД) и COVID-19-инфекцией в возрасте от 4 до 17 лет. Диагноз COVID-19 был установлен на основании положительного ПЦР мазка из носоглотки.

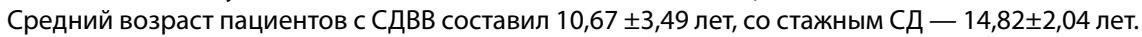
Среди пациентов с СДВВ ДКА при поступлении отмечался в 7 случаях, из них у 3 пациентов - ДКА тяжелой степени, в 1 случае - крайне тяжелый гиперосмолярный гипергликемический синдром. Кетоз при поступлении выявлен у 5/17 пациентов, у остальных 5 пациентов СД манифестировал с гипергликемией без кетоза. Средний уровень гликированного гемоглобина $\left(\mathrm{HbA}_{1 c}\right)$ у пациентов

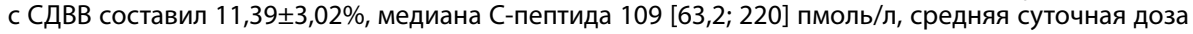

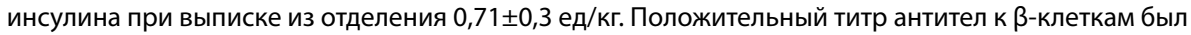
выявлен у 12 пациентов, отрицательный - в 4 случаях, среди них у 2 пациентов отмечался положительный титр антител к GAD и фосфотирозинфосфатазе, у 2 пациентов аутоиммунные маркеры СД1 типа были отрицательными.

Среди пациентов со стажным СД ДКА при поступлении отмечался в 1 случае, декомпенсация СД с кетозом в 1 случае, стойкая гипергликемия в 3 случаях, у одного пациента поводом для госпитализации в отделение послужило тяжелое гипогликемическое состояние. Средний уровень НbA co- $_{1 c}$

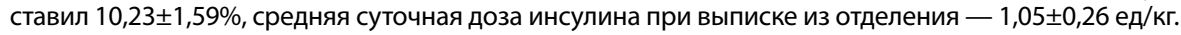

Бессимптомное течение COVID-19 отмечалось у 9/23 пациентов. В 11/23 случаях зарегистрирован острый ринофарингит, в 1 - обструктивный бронхит, в 1 - двусторонняя полисегментарная пневмония. У одного пациента течение COVID-19 сопровождалось развитием тяжелого гемофагоцитарного синдрома с полиорганной недостаточностью и отеком головного мозга. Аносмия отмечалась у 2 пациентов. Антибактериальная терапия применялась у 4 пациентов. Пациенту с тяжелым гемофагоцитарным синдромом была назначена комплексная терапия, включавшая антибактериальные, противовирусные, иммуносупрессивные и противовоспалительные препараты.

ЗАКЛЮчЕНИЕ. Представлены клинические характеристики пациентов с декомпенсированным и впервые выявленным СД и COVID-19 инфекцией. Несмотря на то, что в подавляющем большинстве случаев (20/23 (87\%)) отмечалось бессимптомное или легкое течение COVID-19, а тяжелое течение инфекции наблюдалось только у 2/23 пациентов (8\%), возможность развития гемофагоцитарного синдрома требует пристального внимания к данной группе пациентов и своевременного назначения патогенетической терапии. 